\title{
Caminos que llevan hacia alguna parte: Sobre el método en las relaciones internacionales
}

\author{
Paloma Garcfa Picazo \\ Departamento de Ciencia Política y de la Administración \\ U.N.E.D. \\ pgarcia@poli.uned.es
}

El sistema social es un sistema abierto: abierto a la búsqueda de nuevos fines, sólo se reproduce cambiando.

Jesús IBÁÑEZ, El regreso del sujeto. La investigación social de segundo orden (1991: 29)

Cada historia de las que intervienen en la suma sobre historias describirá no sólo el espacio-tiempo, sino también todo lo que hay en él, incluido cualquier organismo complicado, como seres humanos que pueden observar la historia del universo.

[...] nuestro universo no es simplemente una de las posibles historias sino una de las más probables.

Stephen HAWKING, Historia del tiempo (1988: 182, 183)

Todos los grandes adelantos han surgido de la duda acerca de lo establecido, del valor para liberarse de ello y de la busca y deseo de la verdad. La duda, la búsqueda de la verdad y el valor de emprender una dirección nueva están íntimamente unidos.

Hedwig BORN, «La responsabilidad política del científico», Deutsche Volkszeitung (1957) [Ciencia y conciencia en la era atómica, 1971: 181]

El método amenaza tanto con fetichizar lo estudiado como con degenerar él mismo en fetiche.

Theodor Wiesengrund ADORNO, «Sociología e investigación empírica» (1957) [Epistemología y ciencias sociales, 2001: 23] 
Una formación geológica básica - aunque subsidiaria, en tanto que precisa de ríos que fluyan sobre estructuras de génesis más arcaica- es el aluvión. Como acúmulo de materiales llevados por una corriente, el aluvión es un depósito marginal de aspecto desordenado, amontonado por arrastre y sedimentación, inestable y confuso, heterogéneo y bastante aleatorio. Al menos, en apariencia. En él parece posible encontrar cualquier cosa: minerales, desechos vegetales, osamentas y cadáveres, un par de botas de goma, el collar de la abuela. La historia de los aluviones es irrelevante para los domingueros, que instalan sus pertrechos en sus cercanías, pero no para geólogos, pescadores, labradores, pastores, barqueros, arqueólogos, ingenieros, buscadores de tesoros y halladores de pecios, entre otra gente curiosa. Es posible que fuese desde un aluvión desde donde Heráclito de Éfeso dijera que «descendemos y no descendemos a los mismos ríos, somos y no somos». ${ }^{1}$ De eso se trata en las páginas que siguen.

\section{PARA ENTRAR EN MATERIA: UN ALUVIÓN ERIGIDO EN DOCTRINA}

«Se ve lo que se sabe», sentenciaba, certero, Goethe. Una realidad de aspecto amorfo para el observador superficial es un libro abierto, repleto de signos y símbolos inteligibles, para ojos avezados. El género teórico y metodológico empleado en la materia académica denominada relaciones internacionales ${ }^{2}$ se ha amontonado, institucionalmente desde 1919, en forma de aluvión, depositado en los márgenes de otros saberes más tradicionales como la Filosofía política, la Historia, el Derecho internacional, la práctica y la historia diplomáticas (Merle, 1976; Medina, 1983; Del Arenal, 1987; Barbé, 2003: 23-32; List, Behrens, Reichardt, Simonis, 1995; Van der Pijl, 1996). Hasta comienzos de la década de 1980 su aspecto ha sido más bien confuso (Halliday, 1994: 1-22, 236-244; Walker, 1989). Se debatía entre una preeminencia del discurso ideológico, diversamente enmascarado de cientificismo, una historia hipostasiada en Grands Récits -pues no hay sólo uno - de la especie más infatuada, y un apelmazamiento en el sentido de tejido carente de estructura (Moles, 1978) - de enfoques metodológicos subordinados a lo anterior, de endeble consistencia. Esto se refleja en una producción más cientificista que científica, sometida desde el último tercio del siglo XX (Halliday, 1994: 23-46) a una incisiva revisión por diversos teoricos y metodólogos de las RRII. Y así el aluvión primordial se parece cada vez más, y poco a poco, a la «Sima de los Huesos» del yacimiento de Atapuerca: una estructura de andamios, recorrida por febriles buscadores de hallazgos que extraer del magma informe de un entorno al que también se le hace hablar, pues contiene pólenes, cenizas y otras trazas significativas. Es sabido que bastantes

\footnotetext{
${ }^{1}$ Fragmento original (49 a) en la edición de BRUN (1965).

${ }^{2} \mathrm{~A}$ partir de ahora mencionadas en el texto como RRII.
} 
de las llamadas «rocas metamórficas» son sedimentos originarios sometidos, en largos ciclos geológicos, a procesos tectónicos que cambian, estructuralmente incluso, sus propias determinaciones físicas. Y así, las RRII pueden pasar de ser un aluvión de géneros teóricos a convertirse en una estructura epistémica, siquiera en proceso.

\section{LA HIPÓTESIS DEL SUJETO ANTE LA HIPÓTESIS DEL OBJETO DE SU INVESTIGACIÓN}

Todo lo anterior se refiere al orden del pensar las $R R I I$, pero es evidente que también existe en ellas un orden del hacer. Y ésta es otra cuestión. Parece que los ejecutores de las RRII como «política internacional» no se inclinan a enterarse de ello, entre otras razones porque hay académicos dispuestos a fabricar pseudoteorías y pseudométodos de inmediata aplicabilidad sobre una realidad internacional sometida a padecer luego los efectos de ciertas concepciones erróneas de lo que, en sí, es - debería ser- el «[buen] gobierno del mundo», materializadas en forma de guerras, conflictos eternizados, injusticia, insolidaridad, explotación y saqueo del planeta Tierra y de las gentes que lo habitan. Este último binomio es, junto con la naturaleza naturante que constituye el medio ambiente o ecosistema de una vida social organizada, el ecúmene global (Morin y Kern, 1993) que, en postrer término, forma el objeto final que estudiar desde unas RRII impregnadas de conciencia crítica y reflexividad epistémica. Pero, dentro del ecúmene global, ¿qué objeto o parcela específica, relevante y significativa de la realidad es lo que examina y analiza el investigador de las RRII? ¿La Sociedad, la Comunidad o el Sistema internacionales? ¿Los tres en conjunto o por separado? ¿Varían las RRII si se producen en uno u otro?

\section{1. ¿Tres modelos universales de sociabilidad humana?}

Por resumir los términos de un más que amplio debate antropológico (LéviStrauss, 1992: 242; Montagu, 1988), digamos que la sociabilidad humana habría generado, a lo largo de siglos de evolución abierta, la noción de una sociedad humana virtualmente extendida a todo el planeta (hipótesis o metáfora de la civitas maxima), configurada a partir de la conjunción de relaciones entre diversas comunidades políticas de distintos origen, entidad y formacion: reinos, imperios, ciudades-estado, naciones, etc. (Watson, 1992; Wight, 1991; Truyol y Serra, 1993 [1973]; Medina, 1983; García Picazo, 2000). Como tal, este esquema proviene del estoicismo y culmina, en lo que respecta al mundo antiguo, en Cicerón (Sandbach, 1994: 140-148, 149-178; Truyol y Serra, 1989: 173-225; García Picazo, 2000: 49-82). La vida política del ciudadano -que, según el estoicismo es cosmopolita, o virtual ciudadano de una pólis mundial - se configura sobre 
un esquema de círculos concéntricos, que organizan los grados de su sociabilidad sobre planos que van desde la inmediata proximidad al individuo (familia, comunidad del parentesco biológico y social: tribu, clan) hasta su ámbito más lejano (humanidad, mundo, cosmos), pasando por otros grados intermedios (gentes, pueblo, ciudad, nación, Estado...) (García Picazo, 2000: 97).

Históricamente, esto ha dado lugar, 1. a partir del siglo XV y desde Occidente para el resto del mundo, a un modelo de cristalización política universalizada sobre la base del Estado nacional que concibe la realidad del ámbito internacional como Sociedad Internacional (Watson, 1992). Esta es, en sí, una evolución del denominado «sistema de Estados» europeo, que contempla la existencia de un Derecho internacional público, a su vez, evolutivo, como elemento regulador de sus relaciones mutuas. 2. Pero, por encima de esta estructura -o subyacente a ella, según otras perspectivas - existiría además otro tipo de articulación, ahora axiológica, construida sobre sistemas de valores y creencias, que avalaría la hipótesis de una Comunidad Internacional fundada en criterios normativos, por ejemplo, del tipo de los contenidos en la Carta de Naciones Unidas (1945) o en la Declaración Universal de los Derechos del Hombre (1948). (Bull, 1977; Bull y Watson, 1984). 3. Entretejida con ambas concepciones, aún es posible una configuración más, cuya determinación reviste caracteres más complejos y conceptualmente más incisivos. Se trata de la noción de Sistema Internacional [o Mundial o Global], acorde con visiones actuales como la de «sociedad red» (Castells, 1998; Hannerz, 1998), que dinamizan el análisis con la introducción de factores como la economía, la ciencia, la tecnología, las comunicaciones, la dinámica de los movimientos sociales asociados a la opinión pública, a los fenómenos identitarios, a la irrupción de lo local o lo religioso en la vida internacional, etc. (Merle, 1985, 1991; Barbé, 2003; King, 1991; García Picazo, 2000, 2004 a), b) c)).

En sentido primario y prescindiendo de la terminología empleada - cuyas distinciones importan en tanto que conceptualizan a la realidad internacional con determinaciones de método - tanto la Sociedad, como la Comunidad, como el Sistema internacionales, forman el escenario en el que se desenvuelve la actividad de los actores internacionales, influidos por unos factores que configuran el medio internacional, que algunos, como Merle, llamaron un día la «vida internacional» (1965). Esa actividad relacional entre comunidades políticas y otros actores de la escena internacional, regida por normas jurídicas y convencionales y sometida a regularidades funcionales observables de forma empírica, es lo que, un tanto tautológicamente, se concibe como RRII y que, por extensión, se aplica también al estudio que se realiza de ellas. 


\subsection{El sujeto pensante/actuante de las relaciones internacionales ante su objeto}

Decisivo es, en este punto, el papel del sujeto, tanto el pensante o «investigador» de la realidad, como el actuante, o «ejecutor» de decisiones políticas sobre esa misma realidad (Martín Santos, 1991: 5-23). Pues ese sujeto es quien debe, desde un principio, proponerse establecer los horizontes de esa realidad que aborda - teórica y empíricamente - y delimitar su campo; abstraer los conceptos que la acotan y, eventualmente, la operativizan luego; trazar los métodos o caminos para recorrerla de forma adecuada; orientar los fines de su labor sobre criterios de veracidad; y, en suma, establecer una teoría o conjunto de proposiciones de valor general, lo más veraces y ciertas posibles, que den cuenta de una actividad que, ante y sobre todo, debe ser útil. Cabe ahora preguntar: útil ¿para qué y quién? En términos del postulado aristotélico sobre el logro de una «vida buena y justa en la pólis» - con Neufeld, «global» (Neufeld, 1995) - esa utilidad se funda en algo tan desacreditado para algunos insensatos - y tan valioso para una mayoría moral de personas - como es el bien común de la humanidad, vista como la especie humana en su conjunto, inseparable del ecosistema que la sustenta desde el propio origen de Gaia (Lovelock, 1993), y que incorpora no sólo a la vida, en sentido genérico, sino a una filosofía cosmológica en la que el principio antrópico (Hawking, 1988: 166-187) ocupa un lugar esencial (Galtung, $1984,1990)$. Se parte de lo que define el propio proceso del conocimiento desde la posición actual del saber más exigente: la noción de consciencia, o de ciencia con conciencia, o de reflexividad, o de investigación de segundo orden (Heisenberg, 1947: 73-107, 1985; Schrödinger, 1990: 9-20, 39-51, 53-82; Idem, 1988: 79-123; Idem, 1985: 61-67; Maturana y Varela, 1990: 204-211; Atkins, 1995: 1433; Moya Espí, 1992: 26-45 y Davidson, 1992: 153-161; Prigogine y Stengers, 1990: 113-136; Morin, 1982: 253-310; Bunge, 1985; Ibáñez, 1990: 23-45; Bernal, 1979: 442-476).

\section{VERACIDAD TEÓRICA Y CERTEZA METODOLÓGICA EN LAS RELACIONES INTERNACIONALES: LA IDENTIFICACIÓN DE LO REAL}

Como es sabido, desde la optica cartesiana fundada en la frase "cogito ergo sum «, el sujeto asciende a categoría quasi-omnímoda de un conocimiento del que se predica un tipo específico de racionalidad, con una fuerte implicación matemática y una intensa cualidad analítico-disyuntiva, que es la base del progreso científico occidental desde el siglo XVII (Hazard, 1988: 107-108, 115118). Esta visión, evolucionada en distintas ramas y variaciones, según un esquema similar a las estructuras bifurcantes, propuesto por Ilya Prigogine («metamorfosis de la ciencia», Prigogine, 1990: 29-48), ha llevado, desde su 
propia exigencia crítica, a una revisión profunda de sí misma que es, a su vez, fruto del espíritu cultural que la impregna. Se asiste, con estupor de los dogmáticos, a lo que Prigogine llama el »fin del ideal de la omnisciencia en tanto que «el mundo de los procesos en el cual vivimos y que nos constituye, son, si no ilusiones, por lo menos apariencias determinadas por nuestro modo de observación» (ibidem: $300-301$ ).

\subsection{Racionalismo[s]}

Desde la revolución del pensamiento científico generada por los éxitos de la física cuántica y de la teoría general de la relatividad a partir de comienzos del siglo XX - por poner ejemplos tópicos - el racionalismo incorpora un concepto de razón que, sin abandonar a Descartes - al que sitúa en su justa posición, dentro de un estadio evolutivo histórico - lo trasciende y elabora, orientándose hacia formas más precisas y fértiles de entender una racionalidad atenta a la complejidad, la relatividad y la incertidumbre. La razón es, si »quiere ser« razón, evolutiva; la razón evolucionada hace estallar sus marcos de referencia, no para destruirlos, sino para avanzar y ser ella misma, para cumplirse. El mito unificador del saber, de la ética y de la política, cristalizado en un concepto limitado, cerrado y dogmático de razón - la »razón totalitaria « denunciada por la Escuela de Frankfurt (Adorno, 1965: 37-43) - no se sostiene más que por su instrumentalización por las instancias, a veces deletéreas, del poder asociado a un conocimiento instituido como dominio y hegemonía (Morin, 1984: 35-47, 295 306). Esto es algo que un investigador debe saber y tener presente si aspira a que su trabajo ostente una validez...dentro de lo que es el «juego agonal» o desafío impregnado de tensión y creatividad, que es, en buena medida, la esencia del proceder científico (Huizinga, 1987: 43-47, 90-93).

El racionalismo - que un positivista como Comte (Discurso sobre el espíritu positivo, 1844, capítulo I:II, 9.,10.,11.) llama «metafísico» por considerarlo apriorista - contrapone a sujeto - o mente pensante: subjetiva - y objeto como realidad pensable/pensada: objetiva/objetivable - en una relación disociada, dicotómica y, en gran medida, «mítica», pues traduce la visión de un hombre enfrentado al mundo y a la naturaleza, situado en una posición de aprehensión, dominio y predación de ambos, como si de seres pasivos e inertes se tratara. Para Kant, el conocimiento sistemático de los objetos de la experiencia es posible $a$ priori, en tanto que se distingue entre las meras sensaciones y un modo de conocimiento objetivo que responde, a su vez, a los principios generales que rigen su comportamiento. De esa forma, el sujeto se precede y antecede a sí mismo en el objeto de su conocimiento, siendo el científico «la fuente de las leyes universales que descifra en la naturaleza»: «las condiciones de posibilidad de experimentación de un objeto son también las condiciones de posibilidad de su existencia». 
Ese sujeto (hypokeimenon) así hipostasiado se coloca en el centro del sistema, es él quien «impone la ley y el mundo, tal como lo percibe». Desde esa premisa, el punto de partida de Kant se sitúa en el papel activo desempeñado por el hombre en la descripción científica del mundo, sobre la base de la creencia en el lenguaje único de la ciencia (Prigogine, 1990: 120-123). La univocidad de ese lenguaje, preciso, inequívoco, prístino y objetivo, es uno de los supuestos míticos (Eco, 1994) de lo que, por ejemplo, Hans Albert y Karl Popper - aun subrayando su necesidad e importancia- denuncian como una especie de fundamentalismo científico, ligado a la dogmatización de un saber que por su propia naturaleza debe oponerse a ello, pues su validez proviene de su constante puesta en duda y a prueba (Meyer, 1989: 67; Popper, 1992: 83-91; idem, 1994: $17-49,53-66,70-75)$. El saber científico es precisamente aquél que nunca se agota $a$ ni en sí mismo pues es «búsqueda sin término». Al concepto de verdad, Popper opone, mediante la teoría del conocimiento de Jenófanes, la noción de conjetura, semejante a la verdad, pero más fecunda en términos científicos, pues lleva a buscar conocimientos más seguros sobre la base de su formulación hipotética, sujeta a comprobaciones cada vez más rigurosas...que incluso pueden demostrarse como erróneas si se someten a análisis más depurados (Popper, 1988: 144-158).

\subsection{El muy especializado uso del «Sé»}

En el horizonte de este escrito sería inmoderado e intolerable proseguir con las reflexiones apuntadas antes, que apelan a lo más central del debate científico de los, por lo menos, dos últimos siglos. Lo único preocupante es constatar la necesidad objetiva que existe de repetir una y otra vez estas cosas, como si la inercia de una espuria auctoritas fuese imposible de desarraigar. En este sentido, siempre estimula leer a alguien tan poco acogedor - pero tan lúcidamente liberador - como Wittgenstein, en especial, su ensayo Sobre la certeza (1969). Sus frases, cortas, tajantes y simplemente enunciadas, dicen cosas como estas: «[11] No nos damos cuenta de lo muy especializado que es el uso de »Sé«.»; «[80] Con la verdad de mis enunciados se prueba que comprendo esos enunciados»; «[83] La verdad de algunas proposiciones empíricas pertenece a nuestro sistema de referencia.» «[94] Pero no tengo mi imagen del mundo porque me haya convencido a mí mismo de que sea la correcta; ni tampoco porque esté convencido de su correccion. Por el contrario, se trata del trasfondo que me viene dado y sobre el que distingo entre lo verdadero y lo falso.»; «[256] Por otra parte, el juego del lenguaje cambia con el tiempo.»; «[366] ¿Y si estuviera prohibido decir «Sé» y sólo permitido decir »Creo saber «?»; «[432] La declaración "Sé...» sólo obtiene su significado de su conexión con el resto de la evidencia del "saber".». 


\subsection{Teorizar: el vidente invisible}

A personas demasiado imbuidas por el sentimiento de poseer un «sentido común» auténticamente "común» (the non-sense of common-sense), estas cosas les suenan a extravagancia; en esta extravagancia - o discurrir por sendas menos trilladas: el «nomadismo» de Jesús Ibáñez (Del algoritmo al sujeto, 1985 $: 34-47,290$ ss.) - radica la clave indagatoria sobre la reflexión wittgensteiniana sobre la certeza: «[272] Sé = tal cosa me consta como cierta» (Wittgenstein, 1988). La noción de certeza es más exacta para describir la relación del sujeto que investiga con el objeto investigado; al ser crítica y reflexiva implica al propio sujeto en su relación intelectual e intelectiva consigo mismo, obligándole a distanciarse de sí mismo y a contemplarse como objeto real que interviene e interfiere en el proceso de su propia investigación: lo que, por referencia a las ciencias sociales -y desde un positivismo vienés - Ágnes Heller llama «punto arquimédico» o distancia necesaria para obtener conocimiento verdadero acerca de un mundo y ser conscientes de que ese conocimiento se halla en ese mundo (1989: 53). La metáfora de la lente - que cabe relacionar con la filosofía y el oficio artesano de Spinoza (Misrahi, 1990: 12-23; Domínguez, 1988: 22-43 y además tema predilecto de Descartes: Le Monde ou le traité de la Lumière, 1664) - es aquí muy idónea, en tanto que simboliza al vehículo óptico interpuesto entre la realidad y la mirada humana, como prótesis, que, a su vez y como tal, es el producto de una teorización y una empiria científicas previas, susceptible de evolución y perfeccionamiento técnicos posteriores. Partimos de la base etimológica radical que marca el compromiso intelectual de ese Occidente cuyo origen radica en la Hélade donde la «idea» (eídéa, ídéa) es la acción que conecta ver (eído) con saber (eído precedido de digamma, origen del wissen alemán y del wydd gaélico) ${ }^{3}$ y la «teoría» (theoréo) representa a esa misma visión ordenada y generalizada.

El concepto de teoría está presente en cualquier referencia con pretensiones científicas. En todos los campos de investigación, una teoría - sostiene Mario Bunge - es «un sistema de proposiciones (fórmulas) unidas por la relación de deductibilidad (argamasa sintáctica) y un asunto común (argamasa semántica). En una teoría bien organizada toda proposición es, sea una premisa (postulado, definición o dato), sea una consecuencia (teorema) de algunas premisas tomadas conjuntamente». De inmediato, Bunge advierte que en las ciencias «blandas» una «teoría» designa a menudo a una «hipótesis», es decir, un conjunto de proposiciones cuya verificación suele estar sujeta a un grado mayor de incertidumbre que en otro tipo de construcciones teóricas más formalizadas. Las teorías científicas deben ser puestas a prueba, contrastándose sus proposiciones con datos de observación, medición o experimentación. Además, para ser genuinas, deben también, como mínimo, contener «enunciados legales» (no en térmi-

\footnotetext{
${ }^{3}$ Una aproximación básica a la digamma en F.Villar (1991: 171-172).
} 
nos jurídicos, sino gnoseológicos), o sea: «fórmulas que representan regularidades objetivas (leyes)». Por último, las especulaciones científicas - aun con múltiples teorías aplicadas a las diversas ramas del saber, con normas muy diferenciadas: por el momento no es posible una teoría física para las diversas especies de partícula, campo y cuerpo- siempre se refieren a cosas reales. (Bunge, 1985: 51-58; idem, 1985: 13-45).

Los contenidos formales de esta somera exposición recogen los criterios predicados por el denominado "positivismo lógico», al que Bunge añade, en sus obras, un fuerte compromiso ético derivado de una cierta parcialidad filantrópica por parte del científico implicado en el proceso del conocimiento. Popper, crítico - desde la base de su propio origen intelectual en el «Círculo de Viena» (Kraft, 1986; Chalmers, 1987) - con el positivismo lógico, avanza en la definición de un realismo despojado de ingenuidad: un «realismo crítico, hipotético». Una premisa popperiana consiste en figurarse el mundo como lugar que plantea constantes problemas a la vida, que ésta debe solucionar. Una naturaleza sin vida es una naturaleza sin problemas. Los problemas son intrínsecos a la vida, surgen en y por ella, pertenecen a las relaciones entre los seres vivientes y el mundo: «y las teorías que colocamos en el mundo son intentos de solucionar problemas». Para Popper, lo crucial no son las demostraciones de las teorías, sino las refutaciones que se les oponen. A mayor capacidad de hacer frente a esa problematicidad altamente cualificada, mayor validez teórica. Como Einstein, que intuyó su teoría general de la relatividad con anterioridad a su demostración (Pyenson, 1990: 53-65, 306346; Sánchez-Ron, XIII-XLII; Michelmore, s.f.: 63-66), Popper predica que «la teoría precede a la observación», siendo cada teoría una modificación de la que la precede, a su vez (Popper, 1988: 56-58, 98-101, 30-33).

\subsection{Las mentes y los mundos del sujeto}

Soslayando en cierta forma las implicaciones más hondas del debate entre posturas científicas, a menudo enfrentadas desde bastiones epistemológicos irreductibles, que acabo de proponer de modo tan liviano, lo que me interesa extraer del núcleo de las tesis de Popper es la inclusión del sujeto teórico, como ser vivo, en el mundo de la vida, asunto que lleva a una nueva reconsideración de su papel inicial de sujeto (subiectus, hypokeimenon), literalmente, el que «está situado debajo», en una posición de sub-ordinación altamente cualificada, como señalara Heidegger. Ya no se trata sólo de un hipotético sujeto enfrentado al objeto del mundo «real» exterior a su conciencia tanto como a su propia conciencia reflexiva, concebida a su vez como nuevo objeto -objetivable, por tanto- sino de un sujeto que, en términos físicos, está del todo comprendido en y por el objeto que investiga. Lo que quiero subrayar, sin ninguna pretensión falsamente holista por otro lado, es la relativa preeminencia del mundo en el proceso del conocimiento [de sí mismo] por la mente. ¿Hay mente sin mundo que la sustente? La pregun- 
ta es ardua, pues igualmente puede formularse a la inversa: ¿hay mundo sin una mente que lo piense? (García Picazo, 1993).

¿Qué cosa es ese mundo real que rodea al ser humano pensante? Su percepción emana de una fuente que Schrödinger rubrica como «paradoja matemática» como «los muchos egos conscientes con cuyas experiencias se forma un mundo único». Si Leibniz resolvió este problema con su monadología, Schrödinger plantea la concepción de una única mente, inyectando en Occidente la tradición de los Upanishad. Al incorporar esta brizna de pensamiento oriental, Schrödinger no olvida la precisión lógica ni el rigor científico occidentales. Para él, el hecho empírico esencial consiste en que la conciencia nunca se experimenta en plural, sino que es un acto singular. Ahora bien, si es imposible la simultaneidad de la conciencia, no lo es la de la ciencia y esto es lo que ocasiona su avance, su «acumulación causal» (Leibniz, 1984: 26-49; Schrödinger, 1990: 53, 57-58; Copleston, 1984: 53-56). Si en la línea de la evolución de las especies un primer objetivo, a la par que estadio, es conseguir un cerebro - cosa que sólo algunas han emprendido (Washburn y Moore, 1986: 13, 27-33) - un segundo grado lo es configurar una mente. ¿Qué clase de mundo es aquél que ninguna mente ha contemplado?

Schrödinger cuestiona incluso su existencia; la mente humana es el recipiente de la imagen del mundo (Weltbild), ya que «el mundo se da sólo una vez» (Schrödinger, ibidem: 62). Cada mente (como conciencia singular e individual) se da sólo una vez, pero la mente (como reflexividad epistémica sistematizada, organizada, transmisible, codificada y traducible, formalmente enunciada en un lenguaje universal/universalizable) se da tantas veces como es preciso. Siendo el mundo «todo lo que acaece», según Wittgenstein (Tractatus logico-philosophicus: Die Welt ist alles was der Fall ist), lo que se nos dice de él es que comporta devenir y casualidad. Ahora bien, el mundo no constituye un conjunto de cosas indeterminadas (Dinge), sino de hechos ciertos (Tatsachen), que, a su vez, lo determinan (bestimmen). Se da así un proceso circular en el que los hechos configuran su propio acaecer, tanto en lo que es como en lo que no es. Wittgenstein desarrolla su teoría dentro de lo que denomina el «espacio lógico» (logischer Raum) que así deviene en mundo: «los hechos en el espacio lógico son el mundo" (Die Tatsachen im logischen Raum sind die Welt). La proposición logica inversa modifica sutilmente el sentido: el mundo se divide-descompone (zerfällt) en hechos, pero podría añadirse que ello se produce dentro del sistema lógico de la mente humana (lógos), que introduce el universo de las cosas como Dinge (a-temporal, a-espacial, indeterminado) en el mundo de las cosas como Sachen, sometiéndolas a verificación empírica mediante una constricción factual (Tat->Tat-sachen). El término que reúne a Dinge y Sachen en una relación objetiva (Sachverhalt) es el objeto (Gegenstand), literalmente aquéllo que está «situado enfrente», lo que lleva a la definición sustancial de la cosa como «parte constitutiva» (Bestandteil) de una relación objetiva (Wittgenstein, [1921] 1973: 34-36; Heidegger, 1960: 19-20). 
El mundo es aquello que el ser humano puede comprender con su mente; cualquier ampliación del horizonte de la mente comporta una ampliación del horizonte del mundo. Si no es posible determinar la verdad, un absoluto metafísico, sí es apetecible aproximarse a la certeza, acuñada como «posibilidad de verdad» por Wittgenstein en sus Notebooks (Kenny, 1988: 179ss.,69). En cualquier caso, la referencia antrópica a la mente humana como conciencia y vehículo de representación es ineludible; para Heidegger, mundo «es la denominación de la totalidad de lo existente", concepto que abarca a la naturaleza y a la historia y sus mutuas penetraciones, visibles o abscónditas. La «imagen» (Bild) es «un cuadro de la totalidad de lo existente», algo que no es mera «copia», sino «el mundo mismo». Conocemos el mundo, pues, por su representación. Ese mundo como imagen es parte del hombre, está instalada en él y coexiste con él, en él y ante él. Entender esencialmente la imagen del mundo es comprender el mundo como imagen, inserta en el acontecer histórico, o temporalidad cronificada. Lo existente es lo que el hombre representa y elabora; para el hombre no existe nada al margen de su representación. El mundo de lo existente es, en Occidente y desde el Medievo, un ens creatum. Previamente, el pensamiento griego había formulado una teoría de la existencia que en Parménides se expresa mediante la afirmación de que la percepción de lo existente pertenece al ser porque le es propia ( Pues lo mismo es pensar y ser»). Heidegger confiere, no obstante, a lo existente un margen de autonomía - «lo existente no llega a ser existente por el hecho de que el hombre lo contemple en el sentido del representar de la clase de la percepción subjetiva»- desde la base de trascender el eídos platónico, que es «aspecto», mediante el concepto moderno de la «representación» (repraesentatio; Vorstellung). El hombre moderno «lleva ante sí lo existente como un opuesto (repraesentatio)», es decir, re-presenta, «se pone a sí mismo en escena» vista en forma de «ámbito abierto de lo representado universal y abiertamente» (Heidegger, 1960: 79ss.).

\section{FRÓNESIS Y EPISTEME: HACIA UNA MÚLTIPLE DETERMINACIÓN DEL MÉTODO}

«El sujeto epistémico o sujeto del conocimiento, es, como ser consciente, el último observador u observador envolvente», dice Jesús Ibáñez. Por ello, además de envolvente, ese observador está envuelto y es además envoltorio. Los estratos social, físico y vital le son interiores, están en él; «es materia que observa la materia, vida que observa la vida, sociedad que observa la sociedad, espíritu que observa al espíritu». Como ser consciente, es «un sí-mismo que se observa a sí-mismo y que por tanto ya no es sí-mismo, ya no es en-sí, sino parasí» (Ibáñez, 1985: 260). En lo que creo una línea evolutiva de Parménides, Heidegger y Wittgenstein, Ibáñez sostiene que «el universo está construido de tal modo que seamos capaces de conocerlo». El corolario es que «para conocerlo, 
el universo se debe desdoblar en dos partes, una que mira y otra que es mirada, y lo que ve la parte que mira es sólo parte de lo que es». Esta es la genuina Vorstellung siempre parcial expuesta por Heidegger (monádica en el caso de Leibniz), en sí, figuración de un antagonismo dentro del àgón esencial que es el proceso del conocimiento, como recoge Ibáñez de Spencer-Brown (ibidem: 260 y Nota 11). Desde esta premisa la verdad deviene en «local y transitoria», pues tanto la prueba empírica (sobre el «principio de incertidumbre de Heisenberg) como la prueba teórica (sobre el principio de incompletitud de Gödel) resultan imposibles. Esa verdad limitada por lo que, en aparente paradoja se podría llamar muy bien «exigencia de verdad», se transforma socialmente en una res ficta o cosa inventada o fingida, acomodada semánticamente al término «verosimilitud», es decir, verdad simulada o verdad contingente que se asemeja a verdad inmanente. El sistema social precisa, para funcionar, de verdades establecidas como tales (ibidem: 188-189). Cabría añadir que los sistemas sociales mejor fundados son aquellos que reposan en las «verdades» más verosímiles; esta es una razón del progreso humano.

Como hemos visto con Popper, el mundo es un lugar que plantea constantes problemas a la vida, que ésta soluciona; las teorías que los hombres sitúan el mundo son intentos de solucionar problemas. Desde un positivismo lógico congruente, Mario Bunge sistematiza una serie de ocho problemas relevantes para la mente del hombre contemporáneo - lógicos, semánticos, gnoseológicos, metodológicos, ontológicos, axiológicos, éticos, estéticos- a los que la epistemología responde creando ramas respectivas, enunciadas así en su orden lógico: lógica de la ciencia, semántica de la ciencia, teoría del conocimiento científico, metodología de la ciencia, ontología de la ciencia, axiología de la ciencia, ética de la ciencia, estética de la ciencia. Cada ciencia desarrolla una rama filosófica propia, sintetizada y dirigida hacia sus campos correspondientes (lógica, matemática, física, química, biología, psicología, ciencias sociales, tecnología, teorías de sistemas). Este planteamiento tiene, en el caso de Bunge, la ventaja añadida que ya he señalado, como es su fuerte compromiso ético, que le aparta de cualquier deshumanizada neutralidad «científica». Sostiene sin ambages la necesidad de que el proceso del conocimiento sea útil en términos que, además de teóricos, exhiban relevancia pragmática en el plano existencial del hombre y de su entorno eco-psico-bio-social (Bunge, 1985: 24-27). Bunge no sólo no cuestiona, sino que apoya en sus escritos un positivismo lógico orientado hacia el materialismo, por un lado, y hacia el sistemismo, por otro.

El tema del positivismo es uno de los más cruciales para abordar los planteamientos metodológicos de las $R R I I$. En sí, el debate en torno a su validez como base epistémica de la fundamentación teórica de las $R R I I$ ocupa gran parte de la literatura especializada y, como en otras ciencias sociales, no está cerrado. El debate entre los positivistas - pretendidamente, al menos - y los defensores de una teoría internacional construida sobre los fundamentos de eso que se llaman «humanidades», ocupó el centro de las cuestiones teóricas y metodológicas entre 
el comienzo de la década de 1950 y el final de la de 1970; fue arduo y se desarrolló entre autores anglófonos, a ambos lados del Atlántico. Los británicos optaron por las humanidades (Historia, Derecho, Teoría Política, Historia Diplomática...) y los norteamericanos escogieron un positivismo utilitarista ya vigente en la Economía, la Psicología, la Ciencia Política y la Sociología impartidas en sus universidades, para adaptarlo a las RRII (Bull, 1972; García Picazo, 1998, 2003, 2004 a)). El debate comenzó marcado por un desdén recíproco entre ambas tendencias, replegadas sobre sí mismas en una autocomplacencia poco productiva en términos intelectuales. Pero poco a poco, gracias a la contundencia de autores como Bull, Wight, Waltz o el propio Aron, ${ }^{4}$ en algunos de sus escritos incluso «menores», negadores de toda fácil cerrazón sobre criterios de mera autoridad académica o utilidad política inmediata, se ganó en riqueza teórica, incorporando sustanciales mejoras no ya sólo de conceptos, sistemas y modelos de aprehensión de la realidad internacional, sino de métodos y hasta de lenguaje. La revisión neorrealista, tanto como la postmoderna - junto con sus añadiduras - de las $R R I I$, sigue derroteros afines, lo que ha mejorado el conjunto de su acervo teórico (García Picazo, 1998: 99-141, 191-229, 265-290; 2003: 28-30; 2004 a): 87-121, 186-207).

\subsection{Un positivismo lógico bien entendido}

He mencionado ya que el debate en torno al positivismo en las $R R I I$ no está cerrado. Considero bueno que esto suceda, pues implica que los investigadores de las $R R I I$ estén atentos al avance teórico y no se retraigan en una variante del escolasticismo. Para poder negar algo lo principal es saber de qué se trata. A título personal y desde mi posición teórica, no puedo renegar de muchas ventajas del positivismo lógico, quizá porque al pretender desbaratar los últimos residuos de «metafísica» comteana presentes en el positivismo ingenuo deriva hacia una metafísica más límpida. Pero esta preferencia implica por mi parte un rechazo frontal al positivismo conservador, funcionalista, utilitarista y pazguato empleado en los círculos universitario - político-administrativos de los gobiernos preocupados por crear unas $R R I I$ a su imagen y semejanza, es decir, la consagración perpetua de la frase de Lampedusa: cambiemos algo para que nada cambie. Hecha esta declaración, me adhiero con interés y avidez a los progresos hacia una desmitificación y desconstrucción - críticas, reflexivas, creativas e innovadoras - de ciertos presupuestos de razón, racionalidad, verdad, lógica...implícitos en el discurso «oficial» de las ciencias, que, con Barthes, califico de «metalenguajes» o construcciones discursivas fabricadas para procurar «impresiones» de veracidad, certeza, fiabilidad (ficcionismo del «Als Ob» de Vaihinger,

\footnotetext{
${ }^{4}$ Cito, en este punto, sólo a autores, por así decirlo, «comme il faut», es decir, bien instalados en la academia y nada sospechosos de revolucionarismo epistémico o metodológico.
} 
relatado, entre otros, por Ludwig von Bertalanffy o Mario Bunge) (Barthes, 1977: 7-57; Von Bertalanffy, 1986: 62-68). No por «presentar» una determinada teoría, hipótesis, método, modelo, sistema...arropados con un equipamiento de símbolos de veracidad o certeza - sobre la base de una hipotética congruencia discursiva, o lógica, o matemática - llegan éstos a ser verdaderos o ciertos, es decir, reales (Bunge, 1985: 74-75). Ahí, positivismo lógico y estructuralismo desconstructivo tienen un punto de unión que considero vital. Con todo lo que se ha escrito, aún se ha escrito poco sobre la famosa frase de Hegel: «Todo lo racional es real».

Desde el positivismo lógico hay tres cuestiones básicas cuyo examen concierne de forma directa a la teorización y la metodología de las RRII. Mark Neufeld (The Restructuring of International Relations Theory, 1995) guía esta exposicion.

1. La primera cuestión se sitúa en la «teoría referencial del significado», algo ya apuntado como es que el lenguaje científico debe aspirar, al menos, a ser inequívoco, preciso, exacto y definitorio de una relación esencial entre las cosas y las palabras que las designan, a fin de que lo que se dice sea comprobable como cierto. Verdad, como referencia objetiva a lo real, y significado, como verificación lógico-discursiva de un enunciado semántico congruente, muestran desde esta premisa el lazo más estrecho. Como parece evidente, en las ciencias sociales bastantes proposiciones y enunciados contienen un alto componente normativo y/o axiológico, lo que hace difícil su traslación o traducción a términos empíricos...todo ello por no hablar de cuántas aserciones/aseveraciones ostentan, bajo estos supuestos, un carácter «asignificante» (meaningless): flatus vocis.

2. En esa realidad de la que se predican cosas ocurren cosas y esto se produce con arreglo a ciertas regularidades constatables, que suceden con independencia de que existan categorías subjetivas, que, en términos kantianos, serían espacio, tiempo y un sujeto observador. Jacques Monod aporto, hace años (El azar y la necesidad, 1970), reflexiones que no han perdido actualidad:

le es muy necesario al hombre despertar de su sueño milenario para descubrir su soledad total, su radical foraneidad. Él sabe ahora que, como un zíngaro, está al margen del universo donde debe vivir. Universo sordo a su música, indiferente a sus esperanzas, a sus sufrimientos y a sus crímenes. (ibidem: 162; Prigogine, 1990: 30).

El positivismo lógico aboga por una simbólica des-/sus-titución del sujeto observador como conciencia subjetiva al que re-instituye como una especie de dispositivo de registro de esas regularidades observables que, por conexión lógica, expresan derivaciones de regularidades o leyes de generalidad superior. Implícita está siempre la búsqueda de una condición inicial ${ }^{5}$ de la que deducir concatenaciones causales que sirvan a la 
explicación, lo que a su vez determina un orden lógico que establece que a) las relaciones entre una proposición y otra no pueden variar; b) una proposición (explicativa causal) precede -o es simultánea al menos - a la otra; c) la relación debe ser asimétrica en tanto que la denominada variable independiente induce la producción de la dependiente, siendo imposible cualquier reversión lógica. Se trata de un orden secuencial de dependencia invariable entre modos o estados de cuestiones. El método hipotético-deductivo se sitúa en la inicial problematicidad de un acontecimiento que debe ser explicado mediante formulaciones de hipótesis relevantes que irán desentrañando el enigma (Kuhn) y proponiendo las soluciones a la problematicidad aledaña, según esquemas que pueden adoptar figuraciones en cascada o también arborescentes. En este procedimiento se intuye - término proscrito para un positivista lógico - una cierta afinidad con las estructuras jerárquicas piramidales medievales, presididas por una cúspide ocupada por una divinidad instituida como »origen y motor inmovil«, omnisciente, omnipotente y omnicausante, que, según la frase de Einstein, «nunca juega a los dados». El azar y la accidentalidad son así irrelevantes, pues de ellos no cabe extraer ninguna generalización concluyente o significativa. Lo impredecible se sustrae al dominio científico, pues para el positivismo no encaja ni en la probabilidad ni en los grandes números.

3. Las generalidades que se establecen como teorías o conjuntos ordenados de proposiciones que enuncian leyes de las que derivar otras cosas como reglas y métodos, por ejemplo, no pueden entonces ser accidentales, sino que deben ser sistemáticas, formando un armazón estructural basado en proposiciones ciertas que se axiomatizan o se tornan en indiscutibles por el período de validez que cada teoría ostente en el proceso histórico del conocimiento científico (acumulativo y secuencial) que, en Kuhn, se desenvuelve en forma de «revoluciones científicas» (Kuhn, 1987, 1989).

Tres son las derivaciones de estos principios. La primera establece a la «verdad» como una cuestión de «correspondencia» entre lo observable y lo observado, con arreglo a ciertos requisitos de cientificidad (teóricos, empíricos, metodológicos). La segunda instituye la unidad metodológica de las ciencias sobre la base de construir su edificio sobre los sólidos fundamentos de leyes que describen y explican las regularidades observables, lo que permite predecir comportamientos, trayectorias, tendencias, además de la comprobación de cuanto se afirma y la transmisión de los resultados de todo ello a la comunidad científica mediante lenguajes formali-

${ }^{5}$ Las críticas más sólidas a esa búsqueda «mitológica» se resumen en la fórmula del «diablillo de Laplace»; insuperable es la exposición de Prigogine, 1990: 108-112, 120-136, 293-325. 
zados (matemáticos, verbales) con lo que ésta puede comprender, asimilar y eventualmente cuestionar la veracidad/verosimilitud/certeza de lo propuesto. La tercera afirma la naturaleza objetiva -o axiológicamente neutra- del conocimiento científico, lo que implica una escisión o disyunción entre hecho y valor; esto, a su vez, se eleva a norma imperativa del procedimiento científico, donde los «valores no se refieren sólo a creencias o supuestos irracionales o metafísicos, sino a respuestas emocionales ante ciertas situaciones de la investigación.

Mark Neufeld indica que las condiciones generales del positivismo lógico presiden el discurso teórico dominante de las RRII (Neufeld, 1995: 22-38). Ello fue precedido de una escasísima vocación crítica inicial, lo que coadyuva a la preponderancia de esta posición teórica. En este sentido, aun de acuerdo con Neufeld, considero que es posible decir aún algo más. En más de un aspecto se puede afirmar que ni siquiera un positivismo lógico logrado rige el discurso teórico corriente de las RRII; es más, su empleo se ha abierto paso con dificultad y dista de estar generalizado. El positivismo subyacente a las construcciones teóricas de las $R R I I$ es, en su mayoría, una res ficta, un »Como Si«. Si dispusieran de un armazón teórico auténticamente positivista estoy segura de que su estatuto sería superior, entre otras cosas, porque sería imposible que en su investigación y docencia tomasen parte aficionados y dilettantes, es decir, personas de escasa cualificación científica. Se evitaría que políticos, militares y funcionarios en activo y retirados, sin estudios específicos y con inmensas pretensiones doctrinarias; periodistas vinculados a medios de comunicación dedicados a propagar opiniones en detrimento de las informaciones, infatuados de saberes improvisados; cronistas locales con ambiciones de universalidad y de mesianismo providencialista...ocupasen plazas de profesores, analistas e investigadores de las RRII sin ningún crédito real para hacerlo. Cualquiera que repase las estanterías de una librería y vea el género literario rubricado como »relaciones internacionales « puede comprobar lo que digo. Sucede lo mismo que en esos anaqueles de los grandes almacenes donde libros de divulgación científica y de autoayuda pasan por »ensayos» 0 «textos filosóficos».

\subsection{Sendas trilladas y métodos emancipatorios}

Neufeld parte de un supuesto claramente teleológico al concebir su aportación. Lo enuncia en forma de pregunta: ¿por qué las RRII se preocupan tan poco de la emancipación del ser humano ${ }^{7}$ Alentada por esta cuestión, he reflexiona-

\footnotetext{
${ }^{6}$ Uso antiguo de emancipatio en Fustel de Coulanges, 1987: 67-69,94-95; aplicaciones nuevas por Heller y Féher, 1994: 37ss.
} 
do bastante sobre ello. No sigo escuelas ni me identifico con ninguna doctrina.? Comparto con Neufeld la mayor parte de las cosas que dice. Cosas como preocuparse por una reflexividad teórica y crítica, que enuncia como: »reflexión teórica sobre el propio proceso de teorización «. Esto es algo casi idéntico a lo que Jesús Ibáñez repetía siempre. Implica tres consecuencias, por lo menos, influyentes en la actividad teórica y metodológica del sujeto investigador de las RRII:

1. [Ejercicio] de autoconciencia (Selbstbesinnung kantiana) elucidatoria de las premisas subyacentes.

2. [Ejercicio] de reconocimiento de la dimensión político-normativa inherente a los paradigmas [conjuntos de proposiciones teóricas generales, válidas y ciertas durante su período y en su ámbito de vigencia) y a la tradición científica normal [Kuhn] que éstos sustentan.

3. [Ejercicio] de afirmación acerca de que los juicios razonados sobre los méritos de los paradigmas en contienda son posibles, aun en ausencia de un lenguaje de observación neutral.

El primer ejercicio lleva a distinguir, constatar, registrar, analizar, criticar, los muy a menudo inadvertidos presupuestos/prejuicios que subyacen a las construcciones teóricas. El segundo ejercicio desvela la insuficiencia del planteamiento positivista respecto de «verdad como correspondencia empírica con lo real/reificación de la verdad» sobre la base de la dicotomía entre sujeto y objeto. La ciencia desprovista de sujeto no es ciencia, pues ¿qué es ésta sino un producto de la mente humana? Por otro lado, la validación del saber científico es otro producto de la comunidad científica que establece sus requisitos mediante actos sociales, actos de habla inscritos en una historia.

¿Cuántas cuestiones no son respondidas en tanto que no se plantean porque el investigador »teme « fracasar por proponer preguntas calificadas de »irrelevantes «? Neufeld da en la diana al recordar el post-positivismo de Thomas S.Kuhn y Paul Feyerabend, y también al incorporar la noción de «juegos del lenguaje» de Ludwig Wittgenstein, las aportaciones del neo-pragmatismo de la «hermenéutica filosófica» de Hans-Georg Gadamer, los análisis sobre el discurso del poder de Michel Foucault. Los criterios de validez de la ciencia son construcciones humanas, son convenciones adoptadas por comunidades humanas específicas y poseen una determinación cultural, social, histórica, psicológica. Las ideas, las palabras y el lenguaje no son copia ni réplica de lo real, sino su

\footnotetext{
${ }^{7}$ Recurro a Ágnes Heller y Ferenç Féher, María Zambrano, Václav Havel, Hannah Arendt, HansMagnus Enzensberger, Emst Cassirer, Norbert Elias, Juan David García Bacca, Norberto Bobbio, Luis Martín Santos, Jacques Derrida, Michel Foucault, Jürgen Habermas, Theodor Wiesengrund Adorno, Hans Jonas, Mircea Eliade, Hans Küng...además de los que he citado hasta ahora. No sigo a nadie ni me identifico con ninguna escuela. Reflexiono con libertad sobre el pensamiento de los otros. Vuelvo, cada vez más, a los clásicos. Cuestiono cuanto pienso, cada vez que pienso.
} 
traducción. La tesis fundamental de Neufeld a este respecto es que el contenido teórico de las ciencias sociales es inconmensurable, es decir, que los criterios que lo ponderan, valoran, acreditan, carecen de un denominador común que sirva de medida o ratio de validez última.

El tercer ejercicio, por fin, se refiere a la posibilidad de realizar juicios razonados sobre paradigmas concurrentes, aun careciendo de un lenguaje de observación neutro. Si se diera el supuesto de este lenguaje éste permitiría comparar punto por punto los principios, hipótesis, proposiciones y argumentos de los distintos paradigmas, estableciendo después su mayor o menor grado de validez o acierto respecto de la naturaleza del objeto estudiado. Así, unas corrientes, escuelas, paradigmas...podrían ser considerados «mejores» que otros. Bajo este supuesto yace lo que Neufeld llama «mito del marco [teórico]», una especie de jaula conceptual que limita y cercena cualquier expedición fuera de un lenguaje convencional, cualquier exploración de horizontes teóricos más amplios o complejos, cualquier método innovador, lo que empobrece e incluso niega el proceso del conocimiento humano, aterrado - la «angustia cartesiana»- al descubrir que los fundamentos del saber no son ahistóricos, inmanentes y míticamente seguros y ciertos.

El racionalismo aristotélico fijó los márgenes del saber científico -que, desde entonces, se llama épistéme - en un conocimiento apodíctico del orden y la naturaleza del cosmos (Neufeld, 1995: 39-46). Como es sabido, en el orden del pensar griego, la theoría se concibe como «contemplación de lo eterno permanente». Traducido al orden político este mirar sereno se recrea en un orden que es también una imagen que contemplar, fantasma que nunca obtendrá entidad real. Aristóteles habla de la sotería como medio de preservación de ese orden que encauza el movimiento (tò kineîn). El devenir de las cosas (phyómena tà prágmata) le interesa justo hasta el límite en que lo potencial en ellas alcanza su última configuración esencial ('échein tèn èautoû physin) (Mühl, 1928: 47, 27-28). Por entonces physiká y metaphysiká, como es sabido, no tenían las connotaciones actuales; sólo señalaban el orden de unos libros en una estantería. Más allá (metá) de los textos de física estaban otros, los de metafísica. La physiká era la ciencia de la naturaleza (physis), algo que el hombre podía explorar con la razón para, entre otras cosas, mejorar su vida individual y colectiva e incluso...ganar la guerra a los bárbaros, todos, «enemigos naturales» (physei polémioi). Por otro lado, esta distinción entre «civilizados» (Nosotros) y «bárbaros» (Los Otros) y la relación entre ambos es el objeto sine qua non de las $R R I I$, el polo en torno al que gira la totalidad de su discurso desde el origen de la sociabilidad humana en el planeta Tierra (Wight, 1994: 49-98).

La elucidación post-positivista del concepto de épistéme se realiza en gran medida completándola con el concepto de frónesis (phrónesis) (Gadamer, 1990: 132-137, 85-99). Épistéme significa, en antiguo griego, tanto sabiduría como ciencia (wisdom/science; Weisheit/Wissenschaft/Wissen]; sagesse/science; sapienza/scienza); en su término, a la inteligencia, el conocimiento y el saber se 
les unen la pericia y la destreza. Se pregunta Gadamer: «ipuede, sin embargo, la ciencia representar siempre a la sabiduría? ¿También a la sabiduría del bien?» (ibidem: 136)

La frónesis encarna a una inteligencia, a una sabiduría, que se fundamentan además en la cordura, la sensatez y la prudencia. Incorpora el buen juicio y el temple, la presencia de ánimo, la elevación de un talante moral, que, por así decirlo, «humanizan» a una razón especulativa, analítica y pragmática, orientada a la pericia. Recuerda Gadamer que fue Aristóteles quien sostuvo que el concepto de práctica no se formó contra la teoría, sino contra el «espíritu artificial [artificioso]» de la elaboración, diferenciando entre techné, el saber que rige la capacidad de ejecución, y la frónesis, como saber que gobierna a la práctica. Esta dimensión pragmática de la filosofía hermenéutica de Gadamer es esencial. Techné, sin separarse de ella, se subordina a frónesis (ibidem: 112-113). Es la frónesis un elemento esencial de una racionalidad que, en la consideración de los medios que debe emplear la mente para alcanzar un fin dado, nunca pierde la conciencia de ese fin (télos), incardinado en el «mundo de la vida» (Lebenswelt). Si en la determinación de los medios sí existe un elemento de elección, ello no siempre sucede con los fines. Y es que »en la estructura del ser humano-social interviene un determinado conjunto de orientaciones normativas que influye en el proceso del crecimiento del ser humano, marcándole al final de tal modo que sólo encuentra esto, y no otra cosa, natural y correcta« (ibidem: 132). Defensor de la noción de Bildung -formación integral del ser humano (ibidem: 98)-, Gadamer propone que en la elección de un fin se pondere con justeza lo que »es justo para la vida ordenada, para el bienestar de la vida» (ibidem: 132). El juicio razonado implícito en la frónesis no se produce en el contexto atemporal e inmutable de una épistéme que sitúa al observador como un dispositivo neutro de racionalidad, por así decirlo, descarnada, sino en el ámbito mudable y contingente de la vida humanizada y, por tanto, social.

Neufeld adapta esta visión de Gadamer a las RRII, emancipándolas de una concepción de la racionalidad humana restringida a mera aplicación mecánica de elementos eternos, invariables, y avanza hacia la noción más amplia y sutil de una razón que no se siente disminuida por considerar la relatividad de muchos planteamientos, la inconmensurabilidad de las diversas construcciones teóricas, la significación cualitativa y la dimensión hermenéutica y pragmática de los lenguajes, y, por fin, la consideración de los contenidos de tipo político-normativo de los discursos teóricos. A partir de ahí, la reflexividad asoma como predicado esencial de unas $R R I I$ proyectadas hacia una mejora de sus requisitos teóricos y metodológicos. Esto se traduce en dos condiciones básicas: 1. el reconocimiento de la interrelación, por un lado, entre las concepciones de hecho y valor, $\mathrm{y}$, por otro, las determinaciones propias de una comunidad específica en cuanto criterios internos y singulares de significado y validez; y 2 . la disposición de apertura a entablar un diálogo razonado que certifique los méritos respectivos de los paradigmas - o conjuntos de construcciones teóricas relevantes y siste- 
máticas que resumen posiciones teóricas dadas, vigentes durante un período temporal determinado, concurrentes en un proceso de avance científico- que compiten en el estudio de las RRII (Neufeld, 1995: 44-46).

\subsection{Innovación metodológica: retorno al futuro}

En un texto clásico, Martin Wight señaló la recalcitrante resistencia de la política internacional a ser teorizada. El motivo es su mediatización por el lenguaje de la Teoría política y el Derecho, siendo éste el apropiado para el control humano de la vida social. Tanto una como otro son «mapas de la experiencia» $o$ «sistemas de actuación dentro del ámbito de relaciones normales y resultados calculables»; configuran, por tanto, una «teoría de la supervivencia», en sintonía con las posiciones de Popper: teorías que resuelven problemas vitales (Wight, 1966, en: Der Derian, 1995: 32; Der Derian, 1989: 5).

Durante doscientos años, las $R R I I$ se han desenvuelto sobre un corpus de asunciones tácitas fundadas en una homogeneidad cultural consistente fundada en sus orígenes occidentales, en el mutuo reconocimiento de ciertos derechos y obligaciones subyacentes al discurso normativo e ideológico de ese mismo Occidente, que dieron lugar, en tercer lugar, a procedimientos pragmáticos y mediaciones institucionales y legales de variado tipo, como la diplomacia o el denominado «equilibrio del poder». Ello ha configurado dentro de las RRII una estructura social provista de un grado básico de orden e inteligibilidad, constituida en forma de sociedad de Estados que, en ausencia de una autoridad superior, se instituye también como una «anarquía formal». La desaparición, por ser teóricamente insostenible, de una autoridad epistemológica central -llámesela «Dios», el «Soberano», el «Hombre Racional»- ha llevado, en las RRII, a un estado de debate permanente, ocupado en los últimos tiempos en investigaciones críticas y reflexivas. Una de las propuestas más interesantes consiste en analizar las $R R I I$ como un intertexto, a modo de indagación crítica de un área del pensamiento carente de árbitro final de la verdad. La búsqueda emprendida es de sentido y significado, en clave hermenéutica y pragmática. Contempla a las RRII como una "práctica de conocimiento» que, históricamente, se ha separado de los acontecimientos. Las RRII son vistas como el «texto del mundo» (worldtext), en cierta sintonía con el famoso postulado de Schiller: «la historia del mundo es el juicio del mundo» (Weltgeschichte ist Weltgericht).

Por otro lado, esto subraya lo que ya Wight constató como «alienación» de las RRII, tanto a partir de sus relaciones endógenas - posiciones teóricas autorreferentes, inconmensubles, incontestables, autistas - como desde la realidad que pretendidamente reflejan, constituyendo sus géneros teóricos un «ámbito de recurrencia y repetición». La acción de esquematizar los lemas contemporáneos (contemporary slogans) que se pretenden hacer pasar por teoría internacional sirve para emanciparla de su alienación por las instancias del 
poder, al revelar la trama de sus juegos lingüísticos. De ello se desprende una consecuencia clave dentro del horizonte de este artículo: el esclarecimiento del método, inseparable de su elucidación reflexiva y crítica (Der Derian, 1989).

Der Derian suscribe, en este sentido, la propuesta barthesiana: «en un determinado momento, es necesario revolverse en contra del Método, o, al menos, tratarle sin ningún privilegio fundador, como una de la voces de la pluralidad como una visión, un espectáculo montado en el texto, el texto que, de todas todas, es el único »verdadero « resultado de cualquier investigación» [ $\mathrm{sic}$ ] (ibidem: 7). Los pretendidos debates teóricos y metodológicos de las RRII tienen, en su abrumadora mayoría, más de discusiones «políticas» interdisciplinares/interacadémicas que de verdaderos debates sobre la materia concernida: la cosa real que son las RRII. Es más, a menudo ni siquiera puede hablarse de «metateoría» o teoría que teoriza sobre la teoría, sino de querellas político-administrativoinstitucionales que se intenta pasen por científicas. La cuestión crítica no es "cómo nosotros, como téricos, pensamos acerca del mundo, sino cómo pensamos que los demás deberían pensar sobre él», ironiza Der Derian. Esto afecta de forma gravísima a los métodos que se emplean para investigar las RRII, pues se vacían de contenido real. Son un «Como si».

Desde una ótica convencional, tal como se ha desarrollado en cualquiera de los debates habidos del último siglo (García Picazo, 1998, 2003, 2004 a)), los métodos de las $R R I I$ han estado determinados, con toda la carga que esto implica, por los géneros teóricos o paradigmas respectivamente dominantes. En el Primer Debate «Realismo vs. Idealismo» (1919-1949), los métodos fueron los del Derecho, la Diplomacia e Historia Diplomática, la Historia, la Teoría y la Filosofía políticas, comunes a ambas posiciones (más ideológicas que científicas). En el Segundo Debate «Cientificismo vs. Humanidades» (1949-1979), los métodos se inspiraron en un positivismo funcionalista, behaviorista, descriptivo, acrítico y acumulativo, revestido de una matematización y axiomatización exactificantes del discurso (con algunas inclusiones de sistemismo, cibernética y teorías de juegos), para combatir los métodos del debate anterior, lo que generó una respuesta mimética, por un lado, y autista, por otro, en la otra parte (énfasis en una Sociología histórica, en una Filosofía y Sociología de la Historia, en una Historia tipo Grand Récit). En el Tercer Debate «Globalidad vs. Estatocentrismo» (19791989), los métodos prosiguen con un positivismo que acentúa sus funcionalismo, utilitarismo y economicismo, si bien se producen ciertas derivaciones o bifurcaciones hacia una revisión fundamental del discurso teórico: omnipresencia de prefijos neo- y post-. En el Cuarto Debate (en curso desde 1989) se asiste a una revisión, refundación, reestructuración, de todo lo anterior, incorporándose en la teorización y los métodos aportaciones de la Linguíística y la Semántica, la Psicología, la Teoría y Sociología del Conocimiento, la Antropología, las nuevas Matemáticas, la Cibernética, la Teoría de Sistemas, junto con el recurso a las materias y métodos convencionales, si bien depurados, en lo posible, de ingenuidad epistémica y/o cinismo ideológico (García Picazo, 1998, 2004 a)). 
Por teoría y métodos de las $R R I I$ hoy no pasa cualquier construcción cognitivo-semántica presentada como tal, incluidas, de forma especial, aquéllas que asoman revestidas de ropajes como una «nueva entidad», una «mayor autenticidad» o una más acentuada «pureza disciplinar». Esto es, en sí, una etapa ya superada. El estudioso de las RRII debe ser alguien con un bagaje de conocimientos tan preciso como amplio, que además debe contar con una especie de «hábito mental « (Der Derian, 1989: 8-9, Nota 3) o disposición singular que le permita retener y relacionar la vasta complejidad de lo real tal como se presenta en su dimensión internacional, es decir, lo referido a la sociedad humana más extensa, extrayendo de ella conocimientos y un saber esencial: aquél que, mediante la phrónesis, orienta a la ciencia hacia el fin de lograr la vida del hombre en un universo, quizá indiferente y sordo a sus gritos, como quería Monod, pero consustancial con él. La propuesta metodológica que se ajusta a esa frónesis es, hoy, la de un diálogo intelectual con pensadores tal vez arrinconados y siempre valiosos, con notas a pie de página quizá olvidadas, pero también con grandes textos y autores tradicionales. Se trata de un diálogo «meticulosamente atento con las limitaciones impuestas por el pasado, críticamente intérprete de las voces dominantes del presente, y abiertamente especulativo con lo que puede ser dicho y hecho - si bien escuetamente reflexivo con lo que no - en la política mundial del futuro» (ibidem: 8). En último término, las RRII son una ciencia del hombre, pensada para lograr su supervivencia. Ello implica utilizar los recursos de Occidente, pero también

aprender a detenernos ante el Otro y su diferencia, así como ante la naturaleza y las culturas orgánicas de pueblos y Estados, y a conocer a lo Otro y los Otros como a los Otros de nosotros mismos, a fin de lograr una participación recíproca (Gadamer, 1990: 40). 


\section{BIBLIOGRAFIA}

ADORNo, T.W. (2001) [1972, 1975] Epistemología y ciencias sociales, Madrid, CátedraUniversitat de Valencia.

ATkINS, P.W. (1995) [1992] Cómo crear el mundo, Barcelona, Grijalbo.

BARBE, E. (2003) [1995] Relaciones Internacionales, Madrid, Tecnos.

Barthes, R. et allii (1977) Poétique du récit, París, Du Seuil.

BERNAL, J.D. (1979) [1954, 1957, 1964] Historia social de la ciencia, 2 vols., Barcelona, Península, t.II.

BORN, H. (1957) «La responsabilidad política del científico», Deutsche Volkszeitung en: BORN, M. y H. (1971) Ciencia y conciencia en la era atomica, Madrid, Alianza.

BULL, H. (1966) «Society and Anarchy in International Relations» en: DER DERIAN, J. (ed.) (1995) International Theory. Critical Investigations, Houndmills y Londres, Macmillan, pp.75-93.

BuLL , H. (1972) «The Theory of International Politics 1919-1969» en: DER DERIAN, J. (ed.) (1995) International Theory. Critical Investigations, Houndmills y Londres, Macmillan, pp.181-211.

Bull, H. (1977) The Anarchical Society. A Study of Order in World Politics, Londres, Macmillan.

BuLL, H. y WATSON, A. (1984) The Expansion of the International Society, Oxford, Clarendon Press.

Bunge, M. (1985) [1980] Epistemología, Barcelona, Ariel.

Bunge , M. (1989) Mente y sociedad, Madrid, Alianza.

BRune, J. (1977) [1965] Heráclito, Madrid, Edaf (Estudio Preliminar y selección de textos originales, edición bilingüe).

Castells, M. (1998) La era de la información, 3 vols., Madrid, Alianza.

COMTE, A. (1985) [1844] Discurso sobre el espíritu positivo, Madrid, Alianza.

COPLeston, F. (1984) Filosofias y culturas, México, FCE.

Chalmers, (1987) [1982] ¿Qué es esa cosa llamada ciencia?, Madrid, Siglo XXI.

DavidSON, D. (1992) Mente, mundo y acción, Barcelona, Paidós.

DEL ARENAL, C. (1990) [1984] Introducción a las relaciones internacionales, Madrid, Tecnos.

Der DeRIAN, J. (ed.) (1995) International Theory. Critical Investigations, Houndmills y Londres, Macmillan.

DER DERIAN, J. y SHAPIRO, M.J. (eds.) (1989) International/Intertextual Relations. Postmodern Readings of World Politics, Nueva York, Lexington Books.

DESCARTES, R. (1988) [1637] Discurso del método, Madrid, Alianza.

DESCARTES , R. (1991) [1644] El mundo o el tratado de la luz, Madrid, Alianza.

Domínguez, A. (1988) «Introducción» a SPINOZA, B. Correspondencia, Madrid, Alianza.

ECO, U. (1996) [1993] La búsqueda de la lengua perfecta, Barcelona, Crítica.

Foucault, M. (1991) [1969] La arqueología del saber, México, Siglo XXI.

GADAMER, H.-G. (1990) [1989] La herencia de Europa. Ensayos, Barcelona, Península.

GALTUnG, J. (1984) ¡Hay alternativas! Cuatro caminos hacia la paz y la seguridad, Madrid, Tecnos.

GALTUNG , J. (1990) «Cultural Violence» en: Journal of Peace Research, n² 27, 3, 1990, pp.291-305. 
García Picazo, P. (1993) Mente y mundo. Aproximación sistémica a las relaciones internacionales desde la cultura, Madrid, UCM (Tesis Doctoral).

GARCIA PICAZO, P. (1998) Las relaciones internacionales en el siglo XX: la contienda teórica. Hacia una visión reflexiva y crítica, Madrid, UNED.

García PICAZo, P. (2000) ¿Qué es esa cosa llamada relaciones internacionales? Tres lecciones de autodeterminacion y algunas consideraciones indeterministas, MadridBarcelona, Marcial Pons.

Garcia PICAzo, P. (2003) «Historia y memoria: la reflexividad crítica en las relaciones internacionales» en: IDEM (coord.) La sociedad internacional en el cambio de siglo (1885-1919), Madrid, UNED, pp.21-49).

García PiCAzo, P. (2004) a) Teoría breve de relaciones internacionales, Madrid, Tecnos.

GARCÍA PICAZO, P. (en prensa: otoño 2004) b) «Sociedad/Comunidad internacional: iuna »comunidad imaginada «? en: VV.AA., Comunidad internacional y Sociedad internacional después del 11 de septiembre de 2001, Barcelona, Universitat Pompeu Fabra.

GaRCla PICAZo, P. (en prensa) c) »Globalización y comercio internacional en su perspectiva histórica: una reflexión sobre Immanuel Wallerstein« en: VV.AA. Globalización y comercio internacional, XX Jornadas de Profesores de de Derecho Internacional y Relaciones Internacionales, Madrid, BOE.

Halliday, F. (1994) Rethinking International Relations, Houndmills y Londres, Macmillan.

HANNERZ, U. (1998) [1996] Conexiones transnacionales. Cultura, gente, lugares, Madrid, Cátedra-Universitat de Valencia.

HaWking, S. (1988) Historia del tiempo, Barcelona, Cátedra.

HAZARD, P. (1988) [1961] La crisis de la conciencia europea, Madrid, Alianza.

HEIDEGGER, M. (1979) [1960] Sendas perdidas, Buenos Aires, Losada.

HeISENBERG, W. et allii (1947) La unidad de la imagen científico natural del mundo, Madrid, Cuatro Pliegos.

HEISENBERG , W. (1985) [1955, 1976] La imagen de la naturaleza en la fisica actual, Barcelona, Orbis.

Heller, Á. y FehÉr, F. (1989) [1988] Políticas de la postmodernidad, Barcelona, Península.

Heller, Á. y Fehér, F. (1994) [1992] El péndulo de la modernidad. Una lectura de la era moderna después de la caída del comunismo, Barcelona, Península.

HuIZINGA (1987) [1954] Homo ludens, Madrid, Alianza.

IBÁÑEZ, J. (1985) Del algoritmo al sujeto, Madrid, Siglo XXI.

IBÁÑEZ , J. (1990) »Nuevos avances en la investigación social. La investigación social de segundo orden «, Anthropos, suplemento $\mathrm{n}^{\circ} 22$.

IBÁÑEZ , J. (1994) [1991] El regreso del sujeto. La investigación social de segundo orden, Madrid, Siglo XXI.

KenNy, A. (1988) [1972] Wittgenstein, Madrid, Alianza.

KING, A.D. (1991) Culture, Globalization and the World-System. Contemporary Conditions for the Representation of Identity, Nueva York, Universidad de Binghamton.

KoSELleCK, R. (1993) [1979] Futuro pasado. Para una semántica de los tiempos historicos, Barcelona, Paidós.

KRAFT, V. (1986) [1966] El Círculo de Viena, Madrid, Taurus.

KuHN, T.S. (1987) [1962] La estructura de las revoluciones cientificas, México, FCE. 
KuHN, T.S. (1989) [1987] ¿Qué son las revoluciones científicas? y otros ensayos, Barcelona, Paidós.

LEIBNIZ, G.W. (1984) [1686, 1714] Monadología y Discurso de metafisica, Madrid, Sarpe.

LEVI-STRauss, C. (1992) [1962] El pensamiento salvaje, México, FCE.

List, M., Behrens, M., Reichardt, W., Simonis, G. (1995) Internationale Politik. Probleme und Grundbegriffe, Opladen, Leske + Budrich.

LOVELOCK, J. (1993) [1988] Las edades de Gaia. Una biografia de nuestro planeta vivo, Barcelona, Tusquets.

MARTIN SANTOS, L. (1991) Diez lecciones de epistemología, Madrid, Akal.

Maturana, H. y VARELA, F. (1990) El árbol del conocimiento. Las bases biologicas del conocimiento humano, Madrid, Debate.

Medina, M. (1983) Teoría y formación de la sociedad internacional, Madrid, Tecnos.

MERLE, M. (1965) La vida internacional, Madrid, Tecnos.

MERLE , M. (1986) [1976] Sociologia de las relaciones internacionales, Madrid, Alianza.

MERLE, M. (1991) [1988] Sociología de las relaciones internacionales, Madrid, Alianza.

MEYER, T. (1989) »Fundamentalismo: la otra dialéctica de la Ilustración« en: Debats, $\mathrm{n}^{\circ}$ 32, junio 1990, pp.67-69.

Michelmore, P. (s.f.) Einstein, perfil de un hombre, Barcelona, Labor.

MisRaHI, R. (1990) [1964] Spinoza, Madrid, Edaf.

Moles, A.S. (1978) Sociodinámica de la cultura, Barcelona, Paidos.

MONOD, J. (1986) [1970] El azar y la necesidad, Barcelona, Orbis.

MONTAGU, A. (1988) [1976] La naturaleza de la agresividad humana, Madrid, Alianza.

MorIN, E. y KERN, A.-B. (1993) Tierra-Patria, Barcelona, Kairós.

Morin, E. (1982) [1982] Ciencia con consciencia, Barcelona, Anthropos.

MoYa ESPi, C. (1992) «Introducción» a DAVIDSON, D. Mente, mundo y acción, Barcelona, Paidós.

MứHL, M., (1975) [1928] Die antike Menschheitsidee in ihrer geschichtlicher Entwicklung, Darmstadt, Wissenschaftliche Buchgesellschaft.

NeufELD, M. (1995) The Restructuring of International Relations Theory, Cambridge, Cambridge University Press.

POPPER, K. (1986) [1956, 1982] El universo abierto. Un argumento en favor del indeterminismo, Madrid, Tecnos.

POPPER , K. (1992) [1990] Un mundo de propensiones, Madrid, Tecnos.

POPPER , K. (1988) [1982, 1983] Sociedad abierta, universo abierto, Madrid, Tecnos.

POPPER , K. (1994) [1984, 1992] En busca de un mundo mejor, Barcelona, Paidós.

Prigogine, I. y Stengers, I. (1990) $[1979,1986]$ La nueva alianza. Metamorfosis de la ciencia, Madrid, Alianza.

Pyenson, L. (1990) [1985] El joven Einstein, Madrid, Alianza.

SÁNCHEZ-Ron, J.M. (1990) «Prefacio» a: PYENSON, L. (1990) [1985] El joven Einstein, Madrid, Alianza.

SANDBACH, F.H. (1994) [1975] The Stoics, Londres, Gerald Duckworth.

SCHRÖDINGER, E. (1985) [1951] Ciencia y humanismo, Barcelona, Tusquets.

SCHRÖDINGER , E. (1988) Mi concepción del mundo, Barcelona, Tusquets.

SCHRÖDINGER , E. (1990) [1958, 1959, 1967] Mente y materia, Barcelona, Tusquets. 
STROMBERG, R.N. (1991) [1988] Historia intelectual europea desde 1789, Madrid, Debate.

TruYol y SERRA, A. (1989) [1970] Historia de la Filosofía del Derecho y del Estado. 1. De los origenes a la Baja Edad Media, Madrid, Alianza.

TRUYOL Y SERRA, A. (1993) [1973] La sociedad internacional, Madrid, Alianza.

VAN DER PIJL, K. (1996) Vordenker der Weltpolitik, Opladen, Leske + Budrich.

VILLAR, F. (1991) Los indoeuropeos y los orígenes de Europa, Madrid, Gredos.

Von Bertalanffy, L. (1986) [1975] Perspectivas en la teoría general de sistemas, Madrid, Alianza.

VON BERTALANFFY, L. (1993) [1968] Teoría general de los sistemas, México, FCE.

WALKER, R.B.J. (1989) «History and Structure in the Theory of International Relations» en: DER DERIAN, J. (ed.) (1995) International Theory. Critical Investigations, Houndmills y Londres, Macmillan, pp.308-339.

WASHBURN, S.L. y MOORE, R. (1986) [1980] Del mono al hombre. Un estudio sobre la evolución humana, Madrid, Alianza.

WATSON, A. (1992) The Evolution of International Society, Londres y Nueva York, Routledge.

WIGHT, M. (1966) «Why is There No International Theory?» en: DER DERIAN, J. (ed.) (1995) International Theory. Critical Investigations, Houndmills y Londres, Macmillan.

WIGHT, M. (1994) [1991] International Theory. The Three Traditions, Londres, Leicester University Press y The Royal Institute of International Affairs.

WITTGENSTEIN, L. (1988) [1969] Sobre la certeza, Barcelona, Gedisa.

WitTGENSTEIN , L. (1973) [1921] Tractatus logico-philosophicus, Madrid, Alianza. 


\title{
RESUMEN
}

Como materia universitaria, las relaciones internacionales ostentan una trayectoria relativamente breve: desde 1919 en adelante (Universidad de Aberystwyth y London School of Economics). Ahora bien, como realidad pensada e investigada, su origen se remonta a los principios de la reflexión filosófica (política, jurídica) sobre la sociabilidad humana. Las RRII han atravesado sucesivos debates de fuerte implicación teórica y metodológica en los que el papel del positivismo (neopositivismo lógico) y su contestación estructuralista (postestructuralista) es decisivo. Impregnadas de ideología subrepticia y alienadas por el poder político internacional, las $R R I I$ han emprendido un trabajoso y creativo proceso emancipatorio. Los métodos actuales de las $R R I I$ combinan una exigente revisión del positivismo, desde las perspectivas más incisivas de la ciencia contemporánea, y un redescubrimiento de los clásicos del pensamiento internacional, tratados en clave hermenéutica.

\begin{abstract}
As institutionalized University studies, International Relations show a relatively short path: since 1919 (University of Aberystwyth and London School of Economics). Nevertheless, as thought and researched reality its origin lies on the very beginnings of the philosophical (political, legal) reflection on human sociability. IR have passed through various succesive debates of strong theorical and methodological implications in which the role of positivism (logical neopositivism) and its structuralist response (poststructuralism) is crucial. Impregnated with subreptitious ideology and substantially alienated by the political international power, $I R$ have tackled a laborious and creative emancipatory process. Today's $I R$ 's methods combine a exigent revision of positivism viewed from the most incisive contemporary scientific perspectives, together with a rediscovery of the classical international thinkers, interpreted under a hermeneutical scope.
\end{abstract}

